\title{
Maxillofacial myiasis in a malignant ulcer: Pouring oil on flame
}

\author{
Neha Jain ${ }^{1 *}$, Shaji Thomas ${ }^{2}$, Ajay Pillai ${ }^{1}$ and Ashutoshdutt Pathak ${ }^{3}$ \\ ${ }^{1}$ MDS, Department of Oral and Maxillofacial surgery, People Dental Academy, Bhopal, India \\ ${ }^{2} \mathrm{MDS}$, Department of Oral and Maxillofacial surgery, People Dental Science and Research Center, Bhopal, India \\ ${ }^{3} \mathrm{MDS}$, Department of Oral and Maxillofacial surgery, RKDF College of Dental Science and Research Center, Bhopal, India
}

\begin{abstract}
Myiasis is the parasitic infestation of tissue or organ of animals and human by dipterous larvae (maggots) which lay its eggs on necrotic tissue, open wounds, unbroken skin or mucosa and food. Although myiasis is primarily a disease of cattle and livestock in tropical and underdeveloped countries, human infestation is uncommon and oral myiasis is rarest, found only secondary to systemic illness. Treatment involves manual removal of the maggots with the help of hemostat using turpentine oil with systemic use of Ivermectin, a semi-synthetic macrolide antibiotic. We present a case of 77-year-old female diagnosed with myiasis secondary to squamous cell carcinoma of buccal mucosa, its treatment and review of literature.
\end{abstract}

\section{Introduction}

Although medical science has advanced from the era of Hippocrates to present and contributed a lot to mankind but still fails against the nature's attack in the form of disease. The term myiasis (greek word myia means fly and iasis means disease) was first proposed by Hope (1840) but oral myiasis was first described by Laurence (1909) [1]. Zumpt defined myiasis as the infestation of live human and vertebrate animals by dipterous larva, which at least for certain period, feed on host's dead or living tissue, liquid body secretion or ingested food. ${ }^{2}$ Oral cavity when is invaded by larva of diptera flies, then is termed as oral myiasis.

Myiasis can occur in any place across the world but predominately observed in warm and humid climatic of tropics. A significant association of myiasis has been found with that of unhealthy individual of underdeveloped countries. Musca Nebulo is the most common housefly associated with myiasis in india [2].

Clinically, myiasis can be classified as primary myiasis when caused by by bionthofogas larvae that feed on living tissues. Secondary myiasis is caused by necrobiontophogas larvae flies that feed on necrotic tissues. Based upon anatomic site of infestation, it can be classified as cutaneous, external orifice, internal organs and generalized [3]. Cutaneous myiasis involves the skin which can invade healthy or necrotic wound margin depending on the species of fly involved. Cutaneous myiasis can develop either into painful boil like lesion termed as Furuncular myiasis or Creeping myiasis where the migration of fly larvae occurs underneath the skin. Apart from skin, the eyes, ears, nose and sinuses represent relatively common sites of attack whereas less common sites are mouth, throat, urogenital, and gastrointestinal tracts [4]. Based on degree of dependence on the host myiasis is classified as: (1) 'obligatory myiasis' where fly larvae are completely parasitic upon the host for completion of their life cycle and (2) 'facultative myiasis' where the fly larvae do not depend on host for survival and completion of their life cycle [1].

The incidence of oral myiasis as compared to that of cutaneous myiasis is less because oral tissues are not permanently exposed to the external environment. It is commonly associated with certain anatomical and medical condition. Medical problem favoring the exposure of oral cavity to external environment includes epilepsy [5], Alzheimer's disease [5], mentally handicapped [5], hemiplegia [2], cancrum oris [6], neglected mandibular fractures [6], cerebral palsy [6], patients on mechanical ventilation [6] and anatomical conditions leading to persistent mouth opening (like incompetent lips [6], anterior open bite [6] mouth breathing [6], thumb sucking habits [3]). Poor oral hygiene [6], debilitated person [2], suppuration [6], fermenting food debris associated with poor manual dexterity [2] leading to halitosis attracting flies, alcoholism [6], homelessness [4], periodontitis, low socioeconomic status and close proximity to live stock an environment favoring the flies [2] may further add fuel to the fire. Myiasis was also observed following tooth extraction [6]. We present a case of oral myiasis secondary to squamous cell carcinoma of buccal mucosa.

\section{Case report}

A 77-year-old female patient belonging to a low socioeconomic family residing in rural part of Bhopal, attended to the outpatient department of People college of dental Science and Research Center, Bhopal with the chief complaint of worms seen on the ulcer present on left side of her face since 4-5 days (Figure 1). Past history of Squamous cell carcinoma of left buccal mucosa diagnosed but not treated.

The examination revealed a large necrotic ulcer of approx. 10 X 5 $\mathrm{cm}$ present on left side of face with hundreds of larvae floating on the

${ }^{\star}$ Correspondence to: Neha Jain, Room No 101, Department of Oral \& Maxillofacial Surgery, People's Dental Academy, Bhopal, India, Email: nehamds26@yahoo.in

Key words: oral myiasis, squamous cell carcinoma, dipteran fly, maggot, malignant ulcer, parasitic infestation

Received: June 30, 2019; Accepted: July 12, 2019; Published: July 15, 2019 
edges and depth of the ulcer (Figure 2). The edges of ulcer are indurated and tender on palpation. The patient showed palpable, fixed and painless lymph nodes in bilateral submandibular and cervical region. Based upon the history and presence of maggots, provisional diagnosis of oral myiasis secondary to squamous cell carcinoma was made.

Initially all the maggots located superficially were removed followed by use of turpentine oil impregnated on a cotton bud. Around 150 - 200 maggots were manually removed with the help of tissue holding forceps and removed maggots were sent for entomological examination (Figure 3). The wound was irrigated with saline followed by betadine solution. The same procedure was repeated for two more days. Patient was then referred to Cancer hospital for the management of carcinoma. Maggots were examined by a zoologist and revealed as larvae of Chrysomyia bezziana.

\section{Discussion}

Amongst the various risk factor associated with development of oral myiasis, to our case possible risk factor could be low socioeconomic status, rural area, senility, poor oral hygiene, generalized periodontitis, intense halitosis and necrotic wound due to squamous cell carcinoma may have favored egg laying on the wound where the infestation had developed.

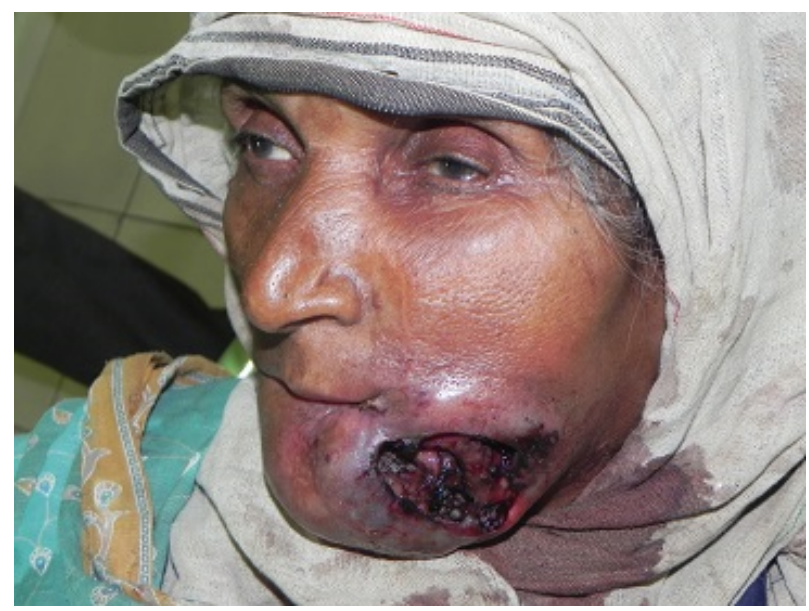

Figure 1. Necotizing ulcer on left side of face

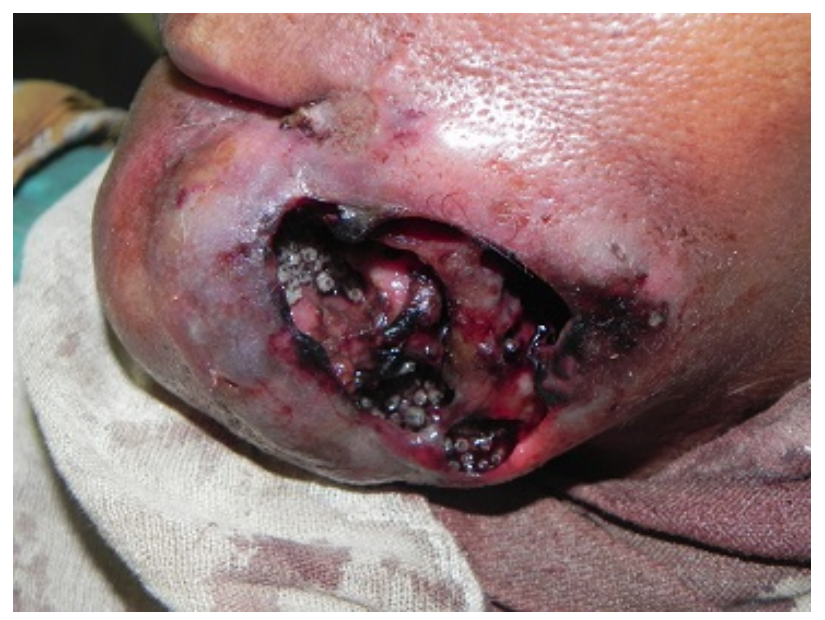

Figure 2. Ulcer wound infested with diptera larvae

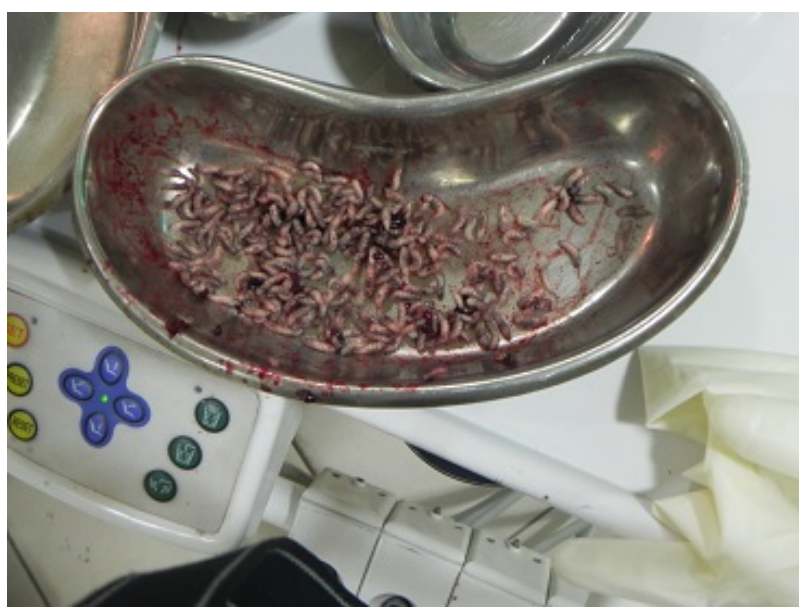

Figure 3. Diptera larvae removed from the wound

Myiasis is caused by Dipteran fly, the life cycle of which begins with egg $\rightarrow$ Larvae $\rightarrow$ pupa $\rightarrow$ adult. During its life cycle, adult fertile female flies are attracted by a wound's odor, feed on exudates, and lay eggs in the injured and necrotic tissues. After 12-24 hours the first instar larvae hatch and enter the living tissues and feed for 5-7 days. Open wound, sores and ulcer provide suitable temperature, moisture and necrotic tissue which is ideal requisite for egg laying and larvae released [2]. The larvae stage last for 5-7 days during which they are parasitic to human beings. The larvae have backward directed segmental hooks with which they anchor themselves to the surrounding tissue. These larvae release toxins to destroy the host tissue. Proteolytic enzymes released by the surrounding bacteria decompose the tissue and the larvae feed on this rotten tissue. They are photophobic and tend to hide deep into the tissues for a suitable niche to develop into pupa. The presence of these hooks makes manual removal of larvae from the host difficult [3]. During feeding on necrotic or living tissue, the caudal end of the maggots with their blackish peritres remain visible on surface of the lesion enabling larvae to breathe [7].

The standard treatment options include maintenance of nutrition, antimicrobials for secondary infection and manual removal of larvae with or without topical asphyxiating drugs which such as ether, chloroform, olive oil, turpentine oil that forces the larvae to come out [1]. Bacon fat, venom extract, lignocaine injection have also been applied in past for facilitating the removal of larva out [4]. Care should be taken not to rupture the maggots as may cause secondary infections or trigger potentially severe allergic reactions. Ivermectin given orally in just one dose of $150-200 \mathrm{mg} / \mathrm{kg}$ body weight and repeated after 24 hours has been reported to be effective in severe cases.

Prevention is better than cure so preventive measures includes basic health care, good hygiene, access to primary health service, and safe water and drainage, control of fly population, basic sanitation and health education [1]. Homeless, aged and debilitating person are groups at risk particularly and special attention should be given in nursing homes for window screening, wound care and oral hygiene. Fly breeding habitats should also be reduced by managing food residues and garbage containers properly [4].

\section{Conflicts of interest}

There are no financial or other relations that could lead to a conflicts of interest. 


\section{Consent}

Informed written consent was obtained from the patient.

\section{References}

1. Maheshwari VJ, GiridharNaidu S (2010) OralMyiasis caused by Chrysomyabezziana: A case report. People's Journal of Scientific Research 3(2): 25-26.

2. Asokan GS, Anand V, Balaji N, Parthiban J, Jeelani S (2013) Maggots in mouthOral Myiasis: A rare case report. Journal of Indian academy of Oral Medicine and Radiology 25(3): 225-228.

3. Sharma J, Mamatha GP, Acharya R (2008) Primary oral myiasis: A case report. Med Oral Pathol Oral Cir Bucal 13: E714-6.
4. Caissie R, Beaulieu F, Giroux M, Berthod F, Landry PE (2008) Cutaneous Myiasis: Diagnosis, treatment, and prevention. J Oral Maxillofacial Surgery 66: 560-568.

5. Freitas DA, Moreira G, Jones KM, Caldeira AP (2012) Social exclusion and myiasis of the upper lip in a Brazilian rural resident. Rural and Remote Health 12: 2188.

6. Droma EB, Wilamowski A, Schnur H, Yarom N, Scheuer E, Schwartz E (2007) Oral myiasis: a case report and literature review. Oral surgery, Oral Medicine, Oral Pathology, Oral Radiology, and Endodontics 103(1): 92-96.

7. Gopalkrishanan S, Srinivasan R, saxena SK, ShanmugapriyaJ (2008) Myiasis in different types of carcinoma cases in Southern India. Indian Journal of Medical Microbiology 26(2): 189-192.

Copyright: (C2019 Jain N. This is an open-access article distributed under the terms of the Creative Commons Attribution License, which permits unrestricted use, distribution, and reproduction in any medium, provided the original author and source are credited. 